\title{
Molecular cloning of the human T-lymphocyte surface CD2 (T11) antigen
}

(T-cell activation/DNA sequencing/cDNA expression library)

\author{
William A. Sewell*, Marion H. Brown*, Jenny Dunne ${ }^{\dagger}$, Michael J. Owen ${ }^{\dagger}$, \\ AND Michael J. CRUMPTON* \\ ${ }^{*}$ Imperial Cancer Research Fund, Lincoln's Inn Fields, London WC2A 3PX, United Kingdom; and †Imperial Cancer Research Fund, Tumour Immunology \\ Unit, Zoology Department, University College, Gower Street, London WC1E 6BT, United Kingdom
}

Communicated by Walter Bodmer, August 4, 1986

\begin{abstract}
CD2 (T11, sheep erythrocyte receptor) is a surface antigen of the human T-lymphocyte lineage. cDNA clones encoding $\mathrm{CD2}$ have been isolated by using the purified, denatured CD2 to raise a rat antiserum. Positive clones were recognized in a phage $\lambda$ gt11 expression library prepared from the human leukemia T-cell line J6. The DNA sequence contained an open reading frame encoding 360 amino acids. The $\mathbf{N}$-terminal 24 amino acids were characteristic of a signal peptide and were followed by a region that matched all 25 residues of the CD2 $\mathrm{N}$ terminus previously determined by amino acid sequencing. The predicted amino acid sequence is consistent with that of a transmembrane glycoprotein containing three potential $\mathbf{N}$-glycosylation sites on the $\mathbf{N}$-terminal side of a 26-amino acid hydrophobic segment. There is a large cytoplasmic domain of $\mathbf{1 2 5}$ amino acids that is rich in proline and in basic residues. RNA blot-hybridization analysis demonstrated hybridization only in those $T$ cells that were positive for surface CD2 antigen. There are limited regions of sequence similarity to members of the immunoglobulin supergene family.
\end{abstract}

CD2 is a surface antigen of the human T-lymphocyte lineage that is expressed on all peripheral blood T cells. It is one of the earliest $\mathrm{T}$-cell markers, being present on $>95 \%$ of thymocytes. It also is found on some natural killer cells but not on B lymphocytes (1-3). Monoclonal antibodies directed against CD2 inhibit the formation of rosettes with sheep erythrocytes, indicating that $\mathrm{CD} 2$ is the erythrocyte receptor or is closely associated with it (1-3). There is evidence that CD2 may mediate T-cell growth, based on observations that $\mathrm{T}$-cell proliferation is initiated by certain combinations of anti-CD2 monoclonal antibodies $(4,5)$ or by sheep erythrocytes (6). T-cell activation required the presence of two anti-CD2 monoclonal antibodies, one of which bound well to activated cells but poorly to resting cells; its epitope was revealed by the binding of the other antibody to resting cells $(4,5)$. There are two recent reports of candidates for a naturally occurring ligand, the action of which may be mimicked by these monoclonal antibodies. A $M_{\mathrm{r}} 42,000$ glycoprotein on sheep erythrocytes, which has been shown to be responsible for the formation of erythrocyte rosettes with T lymphocytes (7), has also been described on sheep leucocytes (8). Another candidate is a soluble factor, released by activated helper $\mathrm{T}$ cells, that stimulated resting $\mathrm{T}$ cells to grow in a fashion similar to that induced by the anti-CD2 monoclonal antibodies (9). Activation of mature $T$ cells through CD2 depended on the secretion of interleukin 2 (IL-2) and expression of IL-2 receptors (4), as is the case with antigen-specific activation via the T-cell antigen receptor $(\mathrm{Ti}$

The publication costs of this article were defrayed in part by page charge payment. This article must therefore be hereby marked "advertisement" in accordance with 18 U.S.C. $\$ 1734$ solely to indicate this fact.
heterodimer-T3 antigen complex) pathway. However, activation of T-cells via $\mathrm{CD} 2$ and $\mathrm{Ti}-\mathrm{T} 3$ appear not to be identical because phorbol esters have been shown to have opposite effects in the two systems. Thus, T-cell proliferation in the presence of a single anti-CD2 monoclonal antibody was induced by phorbol ester (10), whereas prolonged pretreatment with phorbol ester inhibited proliferation elicited by anti-T3 monoclonal antibody (11).

Anti-CD2 monoclonal antibodies are able not only to initiate T-cell proliferation but also to regulate T-cell activation mediated via the Ti-T3 complex. Thus, these antibodies strongly inhibited the proliferation of $\mathrm{T}$ cells induced by specific antigen (12) and anti-T3 antibody (12) as well as by the polyclonal mitogen concanavalin A (13); inhibition of proliferation was associated with lack of both IL-2 receptor expression (14) and IL-2 secretion (13). Delivery of help to B cells (13) and secretion of $\gamma$ interferon (15) were also inhibited, as was T-cell cytotoxicity $(16,17)$.

The apparent importance of CD2 in T-cell activation provides a strong reason for cloning the gene encoding CD2. This communication describes the isolation of CDNA CD2 clones by screening an expression library with antiserum against the purified, denatured antigen. The predicted amino acid sequence of the CD2 antigen has the features of a transmembrane glycoprotein, with distant similarity to the immunoglobulin supergene family, and an extensive, prolinerich basic cytoplasmic domain.

\section{MATERIALS AND METHODS}

Purification of CD2. Purified CD2 was prepared from the human leukemia T-cell line J6 as described (36). Briefly, the antigen was separated from Nonidet P-40-solubilized microsomes by immunoadsorption chromatography with the monoclonal antibody MAR-206 (donated by A. Moretta) attached to Sepharose. The eluted antigen was finally purified by preparative $\mathrm{NaDodSO}_{4} / \mathrm{PAGE}$.

Polyclonal Anti-CD2 Serum. A rat antiserum was prepared by injection of $5 \mu \mathrm{g}$ of purified CD2 at 3-wk intervals. The material was emulsified in complete Freund's adjuvant for the first injection and in incomplete Freund's adjuvant for subsequent injections. All injections were given at multiple subcutaneous sites. Blood was collected 6 days after the third injection. The antiserum was tested by immunoblotting that was performed as described (18).

cDNA Library Screening. A cDNA library, constructed in the phage vector $\lambda g t 11$ (19), was prepared from J6 mRNA (18). Screening was performed as described (18) with the antiserum at a dilution of 1:100. Positive clones were picked and subjected to three further rounds of screening. Library screening by DNA hybridization was performed by standard

Abbreviations: IL-2, interleukin 2; kb, kilobase(s); V, variable; C, constant. 
procedures (20) with a final wash in $0.2 \times \mathrm{NaCl} / \mathrm{Cit}(1 \times$ $\mathrm{NaCl} / \mathrm{Cit}=0.15 \mathrm{M} \mathrm{NaCl} / 0.015 \mathrm{M}$ sodium citrate) containing $0.1 \% \mathrm{NaDodSO}_{4}$ for $1 \mathrm{hr}$ at $68^{\circ} \mathrm{C}$. DNA was labeled with ${ }^{32} \mathrm{P}$ by random hexanucleotide priming (21) to a specific activity of $1-2 \times 10^{9} \mathrm{cpm} / \mu \mathrm{g}$.

DNA Sequencing. Inserts from positive $\lambda \mathrm{gt} 11$ clones were subcloned into the plasmid vector pUC13 or into bacteriophage M13 sequencing vectors. Appropriate restriction fragments were prepared and subcloned into M13. DNA sequence analysis was performed by the dideoxy chain-termination method (22) using ${ }^{35} \mathrm{~S}$-labeled deoxycytidine $5^{\prime}-[\alpha$ thio]triphosphate or [ $\left.{ }^{32} \mathrm{P}\right] \mathrm{dCTP}$. Some sequence data was obtained by specific priming of M13 clones with synthetic 17'-mer oligonucleotides prepared by I. Goldsmith (Imperial Cancer Research Fund, London). The entire sequence was determined on both strands.

RNA Blotting. RNA was prepared by using Nonidet P-40 (23). Preparation of poly(A) ${ }^{+}$RNA, denaturation, electrophoresis in gels containing formaldehyde, and transfer to nitrocellulose were performed as described (20). Filters were hybridized overnight in $50 \%$ (vol/vol) formamide at $42^{\circ} \mathrm{C} \mathrm{(20)}$ with cDNA labeled by random priming (21). The final washes were two incubations for $15 \mathrm{~min}$ each at $50^{\circ} \mathrm{C}$ in $0.1 \times$ $\mathrm{NaCl}$ /Cit containing $0.1 \% \mathrm{NaDodSO}_{4}$.

\section{RESULTS}

Reactivity of Anti-CD2 Antiserum. Purified, denatured CD2 was used to raise an antiserum in rats and to determine the $\mathrm{N}$-terminal 26 amino acid sequence (the latter sequence is shown in Fig. 2 Lower). The rat antiserum was tested by immunoblotting of lysates of J6 cells. It revealed a broad band of $M_{\mathrm{r}} \approx 50,000$, coincident with that obtained with the anti-CD2 monoclonal antibody, RFT11 (Fig. $1 a$, lanes 1 and 3). This band was not detected in lysates of the human lymphoblastoid B-cell line BRI 8 (Fig. 1b, lanes 2 and 4), nor was it revealed by preimmune serum (Fig. $1 b$ ). The band was detected at an antiserum dilution of 1:320 (Fig. 1b). The only other entity specifically revealed by the antiserum was a weak $M_{\mathrm{r}} 25,000$ band (Fig. $1 a$, lane 1; Fig. $1 b$, lanes 1 and 3).

Identification of Clones in $\boldsymbol{\lambda}$ gt11. The antiserum revealed nine positive clones out of $5 \times 10^{6}$ plaques in a $\lambda$ gt 11 library a

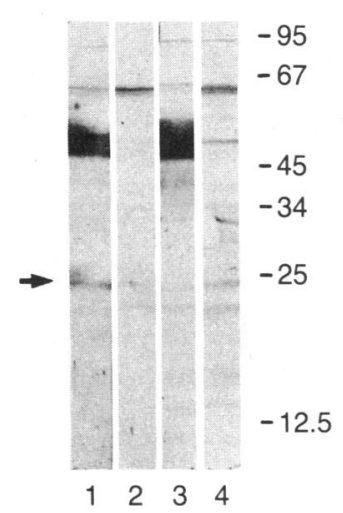

b

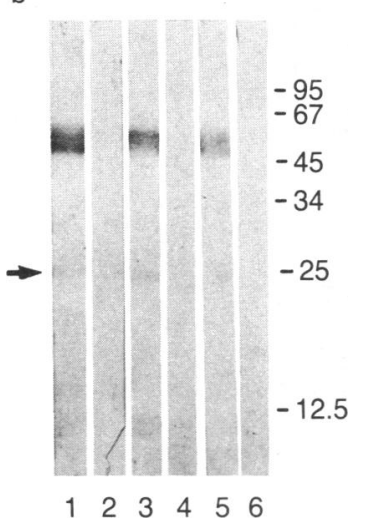

FIG. 1. Immunoblots developed with anti-CD2 antiserum; $2 \times$ $10^{6}$ cell equivalents were loaded per track. (a) Lysates of whole J6 (lanes 1 and 3) and BRI 8 (lanes 2 and 4) cells were developed with the rat anti-CD2 antiserum at a dilution of 1:100 (lanes 1 and 2) or with the monoclonal antibody RFT11 (provided by G. Janossy) at a concentration of $10 \mu \mathrm{g} / \mathrm{ml}$ (lanes 3 and 4). (b) Lysates of J6 cells were developed with the rat anti-CD2 antiserum (tracks 1,3, and 5) and the preimmune serum (tracks 2, 4, and 6) at dilutions of 1:32 (tracks 1 and 2), 1:100 (tracks 3 and 4), and 1:320 (tracks 5 and 6). Molecular weight markers are indicated in $\mathrm{kDa}$. The arrows indicate the weak $M_{\mathrm{r}}$ 25,000 band. containing cDNA prepared from J6 cells. These appeared to be identical, with an insert size of 1.8 kilobases $(\mathrm{kb})$ that detected a similar-size transcript on RNA blot hybridization (data not shown). Preparation of the $\beta$-galactosidase fusion protein from one of these clones (named 138) (Fig. 2 Upper) revealed that the cDNA encoded a polypeptide of about $M_{\mathrm{r}}$ 10,000-15,000 only-i.e., about one-third of the anticipated size of the entire polypeptide. Sequence analysis of clone 138 demonstrated an open reading frame of 335 nucleotides in frame with the $\beta$-galactosidase open reading frame. A probe of $0.75 \mathrm{~kb}$ containing this open reading frame (prepared by using the HindIII site in clone 138; see Fig. 2 Upper) was used to screen the same library by cDNA hybridization. Positive clones were identified at a frequency of approximately 1:30,000. This procedure yielded three independent clones (namely, 141A, 141B, and 254; see Fig. 2 Upper) that extended the open reading frame of clone 138 by $0.76 \mathrm{~kb}$ in the $5^{\prime}$ direction. At the $3^{\prime}$ end, clone $141 \mathrm{~A}$ terminated with a classic polyadenylylation signal (AATAAA) $0.43 \mathrm{~kb}$ downstream from the termination of the open reading frame, followed 13 bases later by a poly(A) tail (Fig. 2 Lower).

Features of cDNA and Protein Sequences. The total cDNA sequence, with the polyadenylylation site of clone 141A, was $1.52 \mathrm{~kb}$ in length, with an open reading frame of 1080 nucleotides encoding a predicted polypeptide of 360 amino acids (Fig. 2 Lower). The first 24 residues consisted of a characteristic signal peptide with an initiator methionine, a very hydrophobic central region (residues -18 to -8 ), and small neutral residues at positions -1 and -3 (Fig. 2 Lower). There were 11 bases of $5^{\prime}$ untranslated mRNA, with a characteristic adenine at position $-3(24)$. The signal peptide was followed by a portion of predicted amino acid sequence that correctly matched all 25 residues of the previously determined N-terminal sequence of the mature $\mathrm{CD} 2$ polypeptide (ref. 36; see Fig. 2 Lower).

The predicted entire amino acid sequence, excluding the signal peptide, encodes a polypeptide chain of $M_{\mathrm{r}} 38,380$, incorporating three potential $\mathrm{N}$-glycosylation sites in the N-terminal half (Fig. 2 Lower). There is an intensely hydrophobic region of 26 residues, characteristic of a transmembrane region, starting at position 186 . This region contains a glycine triplet (positions 194-196) that would enable the molecule to bend within the membrane. On the $3^{\prime}$ aspect of the transmembrane region, the cDNA encodes a strongly positively charged portion, with 7 basic residues in the first 9 positions (residues 212-220). The predicted C-terminal domain has an unusual composition, with 27 prolines, 23 basic residues, and 13 glutamines in the last 100 amino acids. Excluding the $\mathrm{C}$-terminal 6 amino acids, this region contains no acidic residues and no residues with aromatic side chains. There is a repetitive pattern in both the nucleotide and amino acid sequences, most obviously seen at the amino acid positions 257-270, which are homologous to positions 271-284. These particular sequences incorporate continuous runs of 5 and 4 prolines, respectively, and, overall, 9 of 14 amino acids are matched.

RNA Blotting. RNA blotting experiments using the cDNA clone $141 \mathrm{~B}$ as a probe revealed transcripts in preparations of mRNA from activated peripheral blood $\mathrm{T}$ cells, the helper T-cell antigen-specific clone HA1.4 (25), and J6 cells (Fig. 3). At exposures giving a strong signal from J6 mRNA (a cell line that expresses surface $\mathrm{CD} 2$ antigen), there was no detectable signal with mRNA from MOLT -4 or HuT 78 cells and a very weak signal in HS-B2 cells. The latter three T-cell lines were negative for surface CD2 antigen as judged by immunofluorescence. No signals were detected with the lymphoblastoid B-cell lines BRI 8 and Maja. The principal CD2 mRNA species identified by RNA blotting was approximately $1.7 \mathrm{~kb}$; there was also a weak band of about $1.3 \mathrm{~kb}$. 

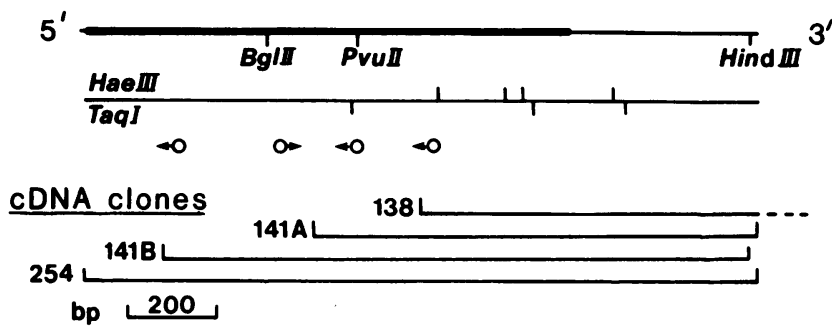

$\frac{-24}{\text { Set Ser Phe Pro Cys Lys Phe Val Ala Ser Phe Leu Leu Ile Phe Asn Val Ser Ser Lys Gly Ala Val Ser Lys glu IIe }}$ CAACCCCTAAG ATG AGC III CCA IGT AAA IIT GTA GCC AGC ITC CTT CTG AIT ITC AAT GIT ICT TCC AAA GGT GCA GIC TCC AAA GAG AIT $10 \quad$ NTS

30

Thr Asn Ala Leu Glu Thr Trp 6ly ala Leu 6ly 6ln Asp lle Asn leu Asp lle Pro ser Phe 6ln Met Ser Asp Asp lle asp asp lle ACS AAT GCC ITG GAA ACC TGG GGT GCC IIG GGT CAG GAC ATC AAC ITG GAC AIT CCT AGT IIT CAA ATG AGT GAT GAT ATT GAC GAT ATA 182

40 so

60

Lys Trp 6lu Lys Thr Ser Asp Lys Lys Lys Ile Ala 6ln Phe Arg Lys Glu Lys 6lu Thr Phe Lys 6lu Lys Asp Thr Tyr Lys Leu Phe AAA IG6 GAA AAA ACT ICA GAC AAG AAA AAG ATT GCA CAA ITC AGA AAA GAG AAA GAG ACT ITC AAG GAA AAA GAT ACA TAT AAG CTA IIT

$\begin{array}{llcl}\text { CHO } & 70 & 80 & 90\end{array}$

Lys Asn 6ly Thr Leu Lys lle Lys His Leu Lys Thr Asp Asp Gln Asp Ile Tyr Lys Val Ser lle Tyr Asp Thr Lys Gly Lys Asn Val

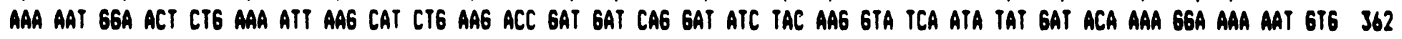

100

110

CHO 120

Leu Glu lys Ile Phe Asp Leu Lys Ile gln Glu Arg Val Ser Lys Pro lys lle Ser Tro Thr Cys lle Asn Thr Thr Leu Thr Cys glu IT6 GAA AAA ATA TIT GAT ITG AAG AIT CAA GAG AG6 GTC TCA AAA CCA AAG ATC ICC IGG ACT IGT ATC AAC ACA ACC CTG ACC TGT GAG 452

CHO $\quad 130$

140

150

Val Met Asn 6ly Thr asp Pro 6lu Leu Asn Leu Tyr 6ln Asp 6ly Lys His Leu Lys Leu Ser Gin Arg Val Ile Thr His Lys Trp Thr 6TA ATG AAT 6GA ACT GAC CCC GAA ITA AAC CTS TAT CAA GAT 666 AAA CAT CTA AAA CTT TCT CAG AGG GTC ATC ACA CAC AAG TG6 ACC S42

160

170

180

Thr Ser Leu Ser Ala Lys Phe Lys Cys Thr Ala gly Asn Lys Val Ser Lys Glu Ser Ser Val Glu Pro Val Ser Cys Pro Glu Lys 6ly ACC AGC CTG AGT GCA AAA TTC AAG TGC ACA GCA G6G AAC AAA GTC AGC AAG GAA TCC AGT GTC GAG CCT GTC AGC IGT CCA GAG AAA 66T 632

190 TM 200 210

Leu Asp Tle Tyr Leu lle lle 6ly lle Cys 6ly 6ly 6ly Ser Leu Leu het Val Phe Val Ala Leu Leu Val Phe Tyr Ile Thr Lys Arg CTG GAC ATC TAT CTC ATC ATT G6C ATA IGT G6A 6GA G6C AGC CTC TTG ATG GTC IIT GTG GCA CTG CTC GTT ITC TAT ATC ACC AAA AGG 722

$220 \quad 230 \quad 240$

Lys Lys 6ln Arg Ser Arg Arg Asn Asp 6lu 6lu Leu 6lu Thr Arg Ala His Arg Val Ala Thr 6lu Glu Arg 6ly Arg Lys Pro His 6ln AAA AAA CAG AGG AGT CGG AGA AAT GAT GAG GAG CTG GAG ACA AGA GCC CAC AGA GTA GCT ACT GAA GAA AGG GGC CG6 AAG CCC CAC CAA BI2

$250 \quad 260 \quad 270$

Ile Pro ala Ser Thr Pro 6ln Asn Pro Ala Thr Ser 6ln His Pro Pro Pro Pro Pro 6ly His arg Ser 6ln Ala Pro Ser His Arg Pro AIT CCA GCT TCA ACC CCT CAG AAT CCA GCA ACT ICC CAA CAT CCT CCT CCA CCA CCT G6T CAT CGT ICC CAG 6CA CCT AGT CAT CGT CCC 902

290

300

Pro Pro Pro 6ly His Arg Val 6ln His 6ln Pro 6ln Lys Arg Pro Pro Ala Pro Ser 6ly Thr 6ln Val His 6ln 6ln Lys 6ly Pro Pro CCG CCT CCT GGA CAC CGT GTT CAG CAC CAG CCT CAG AAG A6G CCT CCT GCT CCG TCG 66C ACA CAA GIT CAC CAG CAG AAA 66C CCG CCC 992

310

320

330

Leu Pro Arg Pro Arg Val 61 In Pro Lys Pro Pro het 61 y 61 in 61 ln Lys Thr His Cys Pro Leu Pro Leu lle Lys Lys Asp Arg Asn Cys

CTC CCC AGA CCT CGA GTT CAG CCA AAA CCT CCC ATG 666 CAG CAG AAA ACT CAT TGT CCC CTT CCT CTA ATT AAA AAA GAT AGA AAC TGT 1082

Leu Phe 6ln

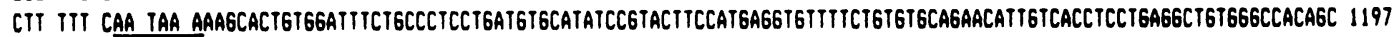

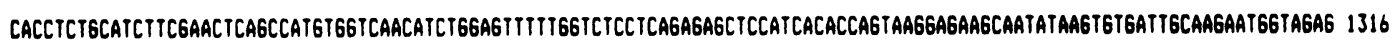

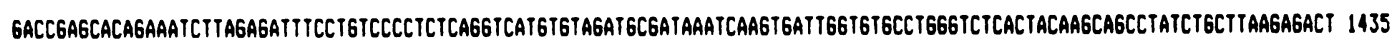

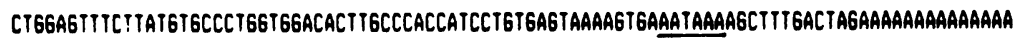

1525

Fig. 2. (Upper) Restriction map of the CD2 antigen cDNA. The top line represents the CD2 cDNA, with the open reading frame indicated by the thick line. Restriction sites used in the sequence analysis are shown. The arrows indicate the site and orientations $\left(5^{\prime}\right.$ to $\left.3^{\prime}\right)$ of synthetic oligonucleotides used as primers in the sequencing program. The positions of the cDNA clones used to define the sequence of the CD2 cDNA are shown. Clone 138 extends to about $1.0 \mathrm{~kb}$ beyond the $3^{\prime}$ end of the other clones, in the direction indicated by the dashed line. (Lower) Nucleotide and predicted amino acid sequence of the CD2 cDNA. Numbers above the amino acid sequence indicate amino acid positions, whereas numbers in the right hand margin show nucleotide positions. The signal peptide (SP), potential N-glycosylation sites (CHO), and transmembrane region (TM) are overlined. The $\mathrm{N}$-terminal 26-amino acid sequence determined by gas-phase sequencing for the purified CD2 antigen (NTS) is also overlined; no amino acid residue was assigned to position 23 (36). 


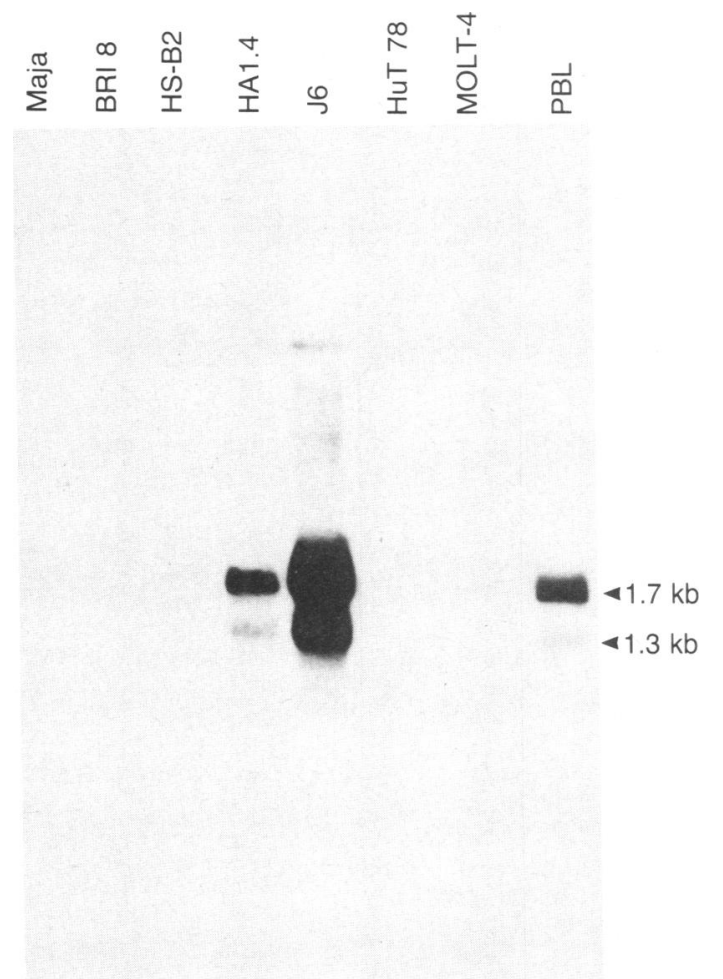

FIG. 3. RNA blot hybridization probed with CD2 cDNA. Poly(A) ${ }^{+}$RNAs (5 $\mu \mathrm{g}$ ) from Maja, BRI 8, HS-B2, J6, HuT 78, and MOLT -4 cells and poly $(A)^{+}$RNAs $(2 \mu \mathrm{g})$ from the helper T-cell clone HA1.4 and from phytohemagglutinin-activated peripheral blood T cells (PBL) were loaded per track. The probe used was the insert from clone 141B that had been labeled $\left(8.8 \times 10^{7} \mathrm{cpm} / \mu \mathrm{g}\right)$ by random priming (21).

Similarity to Other Proteins. The CD2 nucleotide and amino acid sequences did not show any significant similarities to any sequence in the National Biomedical Research Foundation database (K-tuple length $=3$, window size $=20$, gap penalty $=2$ ). However, there were limited regions of similarity between the CD2 amino acid sequence and that of members of the immunoglobulin supergene family. Thus, alignment of the cysteine at position 122 of CD2 with the cysteine at position 23 in the variable (V) domain of the immunoglobulin $\kappa$ light chain $\left(\mathrm{V}_{\kappa}\right.$; the $\mathrm{N}$-terminal cysteine of the intradomain disulfide bridge) revealed a surrounding region of substantial identity (Fig. 4a). No identity was detected with other portions of the $\mathrm{V}_{\kappa}$ domain, nor with other immunoglobulin domains apart from a weak similarity with the constant region heavy chain $\mathrm{C}_{\mathrm{H}} 2$ domain, where the sequence Phe-Lys-Cys-Thr is found in CD2 at positions 160-163, and in the $\mathrm{C}_{\mathrm{H}} 2$ domain surrounding the $\mathrm{C}$-terminal

a

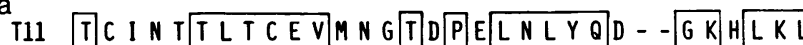

T4 T Q L Q K N L T C E VWW G P TS P K L M L S - . - L L K L

V VGDRVTITCEASQTVLSYLNWYQAKPGKAPKL

b

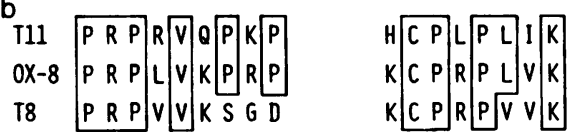

FIG. 4. Similarity of the CD2 amino acid sequence to that of other proteins. Shared amino acid residues are indicated by closed boxes. (a) Residues 114-143 of CD2 are aligned with residues 297-321 of the T4 antigen (26) and with residues $15-46$ of the $V_{\kappa}$ region of human immunoglobulin KA (27). (b) Residues 305-313 and 321-328 of CD2 are aligned with residues 197-205 and 195-202, respectively, of the T8 antigen (28) and of the rat OX-8 antigen (29). cysteine of the intradomain disulfide bond (27). There was even stronger similarity between this region of CD2 (i.e., the extracellular domain adjacent to the transmembrane region) and the corresponding region of the human T-cell T4 antigen. Here CD2 and T4 shared 10 of 21 continuous residues (Fig. $4 a$ ). There was another region where CD2 and T4 shared 8 of 17 continuous residues (residues $167-183$ and 327-343, respectively), although the significance of these matches is questionable because the cysteines in this region are not aligned. In the cytoplasmic domain of CD2, there were two short regions rich in proline and basic residues that were similar to part of the cytoplasmic domain of the human T-cell T8 antigen and its rat equivalent, the OX-8 antigen (Fig. $4 b$ ).

\section{DISCUSSION}

cDNA clones recognized in a $\lambda$ gt11 library of J6 cells by reactivity with a polyclonal antiserum prepared against the purified denatured CD2 antigen have been isolated and sequenced. Several lines of evidence indicate that these clones represent the gene encoding CD2. Most important, the putative $\mathrm{N}$-terminal amino acid sequence encoded by the cDNA matches all residues of the N-terminal 25 amino acid sequence determined for the purified CD2 antigen (Fig. 2 Lower). Furthermore, the size of the predicted polypeptide $\left(M_{\mathrm{r}} 38,380\right)$ and its number of putative $\mathrm{N}$-glycosylation sites (3) are in reasonable agreement with the values determined by $\mathrm{NaDodSO}_{4} / \mathrm{PAGE}$, both for the cell surface glycoprotein (within the range $\left.M_{\mathrm{r}} 50,000-56,000\right)$ and for the non-Nglycosylated polypeptide (about $M_{\mathrm{r}} 40,000$ ) derived by treatment with endoglycosidase F (36). Finally, in RNA blothybridization experiments, mRNA transcription of the gene was coincident with cell surface expression of the antigen. Thus, mRNA was detected in peripheral blood cells, an antigen-specific helper T-cell clone, and J6, a T-cell line known to express surface CD2 but was not detected in B-cell lines nor in T-cell lines that did not express detectable CD2 antigen (Fig. 3).

All of the putative $\mathrm{N}$-glycosylation sites of the predicted $\mathrm{CD} 2$ polypeptide are on the $\mathrm{N}$-terminal aspect of the potential transmembrane region (Fig. 2 Lower), suggesting strongly that the $\mathrm{N}$ terminus is extracellular. On the $\mathrm{C}$-terminal side of the potential transmembrane region is a basic region of the polypeptide (residues 212-220) that is characteristic of transmembrane glycoproteins and is identified in glycophorin and the heavy chain of class I major histocompatibility antigens as being on the cytoplasmic face of the plasma membrane (30). Thus CD2 appears to be a transmembrane glycoprotein with the usual orientation-that is, $\mathrm{N}$ terminus extracellular and $\mathrm{C}$ terminus intracellular.

The size of the major species of mRNA recognized by RNA blot hybridization was $\approx 1.7 \mathrm{~kb}$ (Fig. 3). Use of the polyadenylylation site of clone 141A would yield a mRNA species consistent in size with this band. In this case, there would be a $3^{\prime}$ untranslated region of $0.43 \mathrm{~kb}$ attached to an open reading frame of $1.08 \mathrm{~kb}$ and a $5^{\prime}$ untranslated region of yet undetermined size. There are two possible explanations to account for the minor mRNA species of $1.3 \mathrm{~kb}$ that was also detected by RNA blotting. It may encode the $M_{\mathrm{r}} 25,000$ polypeptide recognized by the anti-CD2 antiserum in immunoblots (Fig. 1). Thus, this smaller polypeptide could be a truncated form of $\mathrm{CD} 2$, derived from full-length $\mathrm{CD} 2$ mRNA by a splicing event. Alternatively, the smaller polypeptide could be a degradation product of the mature CD2 polypeptide, and the minor mRNA band may be generated by use of the polyadenylylation site (AATAAA) that starts in the last codon of the open reading frame and that incorporates the termination codon.

The initial clone recognized by the anti-CD2 antiserum (clone 138) contained at its $3^{\prime}$ end $1.0 \mathrm{~kb}$ of cDNA that was 
not present in the other clones. The $5^{\prime} 0.76 \mathrm{~kb}$ of clone 138 matches clone 141A exactly as far as the first deoxyadenosine residue of the poly(A) tail of the latter clone. In the first 50 nucleotides downstream from this position, clone 138 contains two stretches of the sequence CAYTG (in which Y is an unspecified pyrimidine residue), which is frequently found in genomic DNA in the region of a polyadenylylation site (31). Thus, the sequence of this region is consistent with that of genomic DNA, suggesting that this clone represents an aberrant transcript that failed to employ the normally used polyadenylylation site. Alternatively, the $3^{\prime} 1.0 \mathrm{~kb}$ of clone 138 could be the result of a double-ligation event in the generation of the cDNA library, although this possibility appears unlikely in view of the failure to detect any species of mRNA, apart from the CD2 bands, in blot hybridizations of J6 cells probed with clone 138 (data not shown).

There was significant amino acid sequence similarity between the extracellular portion of $\mathrm{CD} 2$ adjacent to the transmembrane region and the corresponding domain of the $\mathrm{T} 4$ antigen (Fig. $4 a$ ). This region of $\mathrm{T} 4$ was not reported to be immunoglobulin-like (26) but does contain an intrachain disulfide bond between residues 305 and 347 (32). In the corresponding domain of CD2, portions of amino acid sequence around the cysteines at positions 122 and 162 resembled sequences around the $\mathrm{N}$ - and $\mathrm{C}$-terminal cysteines of the intradomain disulfide bonds of $V_{\kappa}$ and $C_{H} 2$ domains, respectively. These homologies suggest that this region of the CD2 gene and the immunoglobulin genes are derived from a common ancestral gene. However, the predicted secondary structure of this region of CD2 does not resemble the characteristic $\beta$-pleated sheet structure of the immunoglobulin fold but is predominantly $\alpha$-helical (33). Thus, CD2 retains some primary structural homology with immunoglobulin but appears to have a different secondary structure.

The cytoplasmic domain of CD2 is large both in absolute size ( 125 amino acid residues) and as a proportion of the total polypeptide $(37 \%)$. The relatively large cytoplasmic domain is reminiscent of transmembrane proteins involved in signal transduction, such as the receptor for epidermal growth factor (34). A large cytoplasmic domain provides, a priori, ample opportunity for interaction with intracellular structures. The large proportion of proline residues in the $\mathrm{C}$ terminal 100 amino acids probably means that this portion of the CD2 antigen assumes an open structure, with a lack of $\alpha$-helices and $\beta$ structure revealed by secondary structure predictions (33). The abundance of proline and basic residues in this domain is reminiscent of the $\mathrm{N}$-terminal 110 residues of the capsid protein of Semliki Forest virus (35). This region of the capsid protein potentially interacts with the viral RNA and/or with the cytoplasmic face of the viral membrane incorporating the transmembrane viral glycoproteins. Based upon this model, it is possible that this portion of the CD2 antigen may have evolved to interact with nucleic acid and/or the plasma membrane's cytoplasmic face.

The authors thank Drs. J. Trowsdale and P. N. Goodfellow for critically reviewing the manuscript; Dr. A. F. Williams for helpful discussion; Drs. H. Kataoka, M. K. L. Collins, and T. Lindahl for the cDNA library; and Kim Richardson for secretarial assistance.

1. Howard, F. D., Ledbetter, J. A., Wong, J., Bieber, C. P., Stinson, E. B. \& Herzenberg, L. A. (1981) J. Immunol. 126, 2117-2122.
2. Kamoun, M., Martin, P. J., Hansen, J. A., Brown, M. A., Siadak, A. W. \& Nowinski, R. C. (1981) J. Exp. Med. 153, 207-212.

3. Verbi, W., Greaves, M. F., Schneider, C., Koubek, K., Janossy, G., Kung, P. \& Goldstein, G. (1982) Eur. J. Immunol. 12, 81-86.

4. Meuer, S. C., Hussey, R. E., Fabbi, M., Fox, D., Acuto, O., Fitzgerald, K. A., Hodgdon, J. C., Protentis, J. P., Schlossman, S. F. \& Reinherz, E. L. (1984) Cell 36, 897-906.

5. Brottier, P., Boumsell, L., Gelin, C. \& Bernard, A. (1985) J. Immunol. 135, 1624-1631.

6. Larsson, E.-L., Andersson, J. \& Continho, A. (1978) Eur. J. Immunol. 8, 693-696.

7. Hunig, T. (1985) J. Exp. Med. 162, 890-901.

8. Hunig, T. (1986) J. Immunol. 136, 2103-2108.

9. Milanese, C., Richardson, N. E. \& Reinherz, E. L. (1986) Science 231, 1118-1122.

10. Holter, W., Fischer, G. F., Majdic, O., Stockinger, H. \& Knapp, W. (1986) J. Exp. Med. 163, 654-664.

11. Cantrell, D. A., Davies, A. A., Krissansen, G. W. \& Crumpton, M. J. (1986) in Regulation of Immune Gene Expression, eds. Feldmann, M. \& McMichael, A. (Humana, New York), pp. 119-133.

12. Van Wauwe, J., Goossens, J., Decock, W., Kung, P. \& Goldstein, G. (1981) Immunology 44, 865-871.

13. Palacios, R. \& Martinez-Maza, O. (1982) J. Immunol. 129, 2479-2485.

14. Reed, J. C., Tadmori, W., Kamoun, M., Koretzky, G. \& Nowell, P. C. (1985) J. Immunol. 134, 1631-1639.

15. Wilkinson, M. \& Morris, A. (1984) Eur. J. Immunol. 14, 708-713.

16. Martin, P. J., Longton, G., Ledbetter, J. A., Newman, W., Braun, M. P., Beatty, P. G. \& Hansen, J. A. (1983) J. Immunol. 131, 180-185.

17. Krensky, A. M., Sanchez-Madrid, F., Robbins, E., Nagy, J. A., Springer, T. A. \& Burakoff, S. J. (1983) J. Immunol. 131, 611-616.

18. Krissansen, G. W., Owen, M. J., Verbi, W. \& Crumpton, M. J. (1986) EMBO J. 5, 1799-1808.

19. Young, R. A. \& Davis, R. W. (1983) Proc. Natl. Acad. Sci. USA 80, 1194-1198.

20. Maniatis, T., Fritsch, E. F. \& Sambrook, J. (1982) Molecular Cloning: A Laboratory Manual (Cold Spring Harbor Laboratory, Cold Spring Harbor, NY).

21. Feinberg, A. P. \& Vogelstein, B. (1983) Anal. Biochem. 132, 6-13.

22. Sanger, F., Nicklen, S. \& Coulson, A. R. (1977) Proc. Natl. Acad. Sci. USA 74, 5463-5467.

23. Favaloro, J., Treisman, R. \& Kamen, R. (1980) Methods Enzymol. $65,718-720$.

24. Kozak, M. (1984) Nucleic Acids Res. 12, 857-872.

25. Lamb, J. R., Eckels, D. D., Lake, P., Johnson, A. H., Hartzman, R. J. \& Woody, J. N. (1982) J. Immunol. 128, 233-238.

26. Maddon P. J., Littman, D. R., Godfrey, M., Maddon, D. E., Chess, L. \& Axel, R. (1985) Cell 42, 93-104.

27. Kabat, E. A., Wu, T. T., Bilofsky, H., Reid-Muller, M. \& Perry, H. (1983) Sequences of Proteins of Immunological Interest (U.S. Dept. of Health and Human Services, Washington, DC).

28. Littman, D. R., Thomas, Y., Maddon, P. J., Chess, L. \& Axel, R. (1985) Cell 40, 237-246.

29. Johnson, P., Gagnon, J., Barclay, A. N. \& Williams, A. F. (1985) EMBO J. 4, 2539-2545.

30. Robb, R. J., Terhorst, C. \& Strominger, J. L. (1978) J. Biol. Chem. 253, 5319-5324.

31. Berget, S. M. (1984) Nature (London) 309, 179-182.

32. Classon, B. J., Tsagaratos, J., McKenzie, I. F. C. \& Walker, I. D. (1986) Proc. Natl. Acad. Sci. USA 83, 4499-4503.

33. Taylor, W. R. \& Thornton, J. M. (1984) J. Mol. Biol. 173 487-514.

34. Ullrich, A., Coussens, L., Hayflick, J. S., Dull, T. J., Gray, A., Tam, A. W., Lee, J., Yarden, Y., Libermann, T. A., Schlessinger, J., Downward, J., Mayes, E. L. V., Whittle, N., Waterfield, M. D. \& Seeburg, P. H. (1984) Nature (London) 309, 418-425.

35. Garoff, H., Frischauf, A.-M., Simons, K., Lehrach, H. \& Delius, H. (1980) Proc. Natl. Acad. Sci. USA 77, 6376-6380.

36. Brown, M. H., Krissansen, G. W., Totty, N. F., Sewell, W. A. \& Crumpton, M. J. (1986) Eur. J. Immunol., in press. 